\title{
Inoculation of Lactobacillus sakei on Quality Traits of Dry Fermented Sausages
}

\author{
Ammara Ameer, Semeneh Seleshe, Beom-Joon Kim, and Suk Nam Kang
}

Department of Animal Resource, Daegu University, Gyeongsan 38453, Korea

\begin{abstract}
In this study, fermented sausage prepared by inoculating different strains of Lactobacillus sakei was assessed for their physiochemical, microbiological, and textural characteristics during fermentation and ripening. Five treatments were prepared: Control (commercial starter culture, C), L. sakei Korean Collection for Type Cultures (KCTC)-3802 (S1), L. sakei KCTC-3598 (S2), L. sakei KCTC-5053 (S3), and L. sakei KCTC-3603 (S4). The different strains of L. sakei did not show substantial differences $(P>0.05)$ in $\mathrm{pH}$ values for dry fermented sausages at the end of the ripening period. Water activity $\left(a_{\mathrm{w}}\right)$ values for all treatments were below $0.85(P<0.05)$. Total viable count at the end of the study decreased in all $L$. sa$k e i$ starter culture inoculated fermented sausages as S3> S2 > S1 $>$ S4. High values of lactic acid bacteria (LAB) count and hardness were observed in the S2 batch as compared to other $L$. sakei inoculated treatments at the end of ripening (21st day). S3 inoculated with $L$. sakei strain exhibited significantly $(P<0.05)$ higher value of a* (redness). A significant difference $(P<0.05)$ in thiobarbituric acid reactive substances was exhibited in the following order: S4>S2>S1>S3>C. This study suggests that inoculation of S3 (L. sakei KCTC-5053) strain can improve the red color and reduce lipid oxidation while S2 enhances better microbiological quality as LAB. Incorporation of S3 and S2 strains accordingly can be helpful to enhance the quality of dry fermented sausages.
\end{abstract}

Keywords: dry fermented sausage, lactic acid bacteria, physiochemical, ripening, starter cultures

\section{INTRODUCTION}

The perishable nature of meat and meat byproducts, caused by factors such as high water and nutrient content of the ground matrix, and the absence of a lactic acid protective microflora, results in spoilage and the production of pathogenic bacteria (Escherichia coli, Staphylococcus aureus, Listeria monocytogenes, Clostridium perfringens, and Salmonella spp.) that cause food-borne illness/diseases (Nastasijevic et al., 2009). Fermentation is one of the bio-preservation techniques used in both new and traditional foods and defined as an energy-producing microbial metabolism in which an organic substrate, a carbohydrate, is incompletely oxidized and an organic carbohydrate serves as an electron acceptor (Buckel, 2021). In turn, the process yields food products with unique characteristics appreciated by consumers. Adams (1990) identified three major benefits of meat fermentation: safety, acceptability, and stability. Fermented meat products are still very popular and manufactured in huge quantities, particularly in Europe, owing to their unique and peculiar sensory qualities, convenience, and alleged culinary and cultural heritage (Leroy et al., 2013). In Spain and Germany, there are more than 50 and 350 types of fermented sausages, respectively (Hutkins, 2006).

A starter culture is a microbiological culture of defined organisms made up of cultivation medium or nutrient liquids colonized by living microorganisms for fermentation (Pilevar and Hosseini, 2017). The incorporation of starter culture into the meat during manufacturing of dryfermented sausage significantly reduces the ripening period. The use of lactic acid bacteria (LAB) as starter culture produces meat products with desirable characteristics and health benefits, as well as contributing to food safety and quality in terms of physiochemical and sensory characteristics (Parvez et al., 2006; Justo et al., 2013). As far as LAB starter cultivation is concerned, Lactobacillus sakei, Lactobacillus acidilactici, Lactobacillus curvatus, Lactobacillus pentosus, Lactobacillus casei, and Pedicoccus pentosaceus are the main species used for the fermentation process (Hugas and Monfort, 1997).

The species name $L$. sakei is derived from its isolation 
and characterization from 'sake', a fermented rice beverage (Katagiri et al., 1934). This species has a lot of genetic variability, which can be seen when looking at different strains, and on which its numerous features in meat products: starter, spoiler, and protective culture, are most likely based. Because of its resilience to a variety of culture conditions and antibacterial properties, $L$. sakei was employed in fermented sausages (Gelinski et al., 2019). The ability to cope with high $\mathrm{NaCl}$ concentrations, acidic $\mathrm{pH}$, or high temperatures vary between $L$. Sakei strains. The aptitude of $L$. sakei strains to fast acidification is an important characteristic as it has an impact on taste and safety, aroma, and bacteriostatic and bactericidal effects (Leroy et al., 2006). L. sakei is also one of the few LAB that has a heme-dependent catalase (Chaillou et al., 2005).

The role of $L$. sakei in the fermentation of different types of meat products of various country origins was reported by several authors (Nguyen et al., 2010; Wanangkarn et al., 2014; Fontana et al., 2016; Tamang et al., 2016). However, the effect of different strains of sakei species on quality characteristics of dry fermented sausages during fermentation and ripening was not conducted to date. We believe that evaluating the functional features of individual strains can help in the selection and production of high-quality fermented meats on an industrial scale, whether they are employed as a single strain or a mix of strains. Therefore, this study was conducted to investigate the quality traits (physicochemical and microbiological) of dry fermented sausage using four different strains of L. sakei as starter cultures: KCTC-3802, KCTC-3598, KCTC-5053, and KCTC-3603 as compared to the control (C), commercial starter culture.

\section{MATERIALS AND METHODS}

\section{Bacterial cultures preparation}

The strains of $L$. sakei were purchased from the Korean Collection for Type Cultures (KCTC, Daejeon, Korea), the Biological Resource Center (BRC) of the Korea Research Institute of Bioscience and Biotechnology (KRIBB, Daejeon, Korea), as lyophilized stocks. The commercial starter culture, Starterkulturen Almi Rohschinken was purchased from the market (Almi GmbH \& Co KG, Oftering, Austria) and used as 5th treatment and positive control. All the strains were enriched with de Mane Rogosae Sharpe (MRS) medium (Becton, Dickinson and Company, Le-Pont-de-Claix, France) at $37^{\circ} \mathrm{C}$ overnight, harvested by centrifugation at $4,000 \mathrm{rpm}$ for $10 \mathrm{~min}$ at $6^{\circ} \mathrm{C}$, and washed and re-suspended in saline solution $(0.85 \% \mathrm{NaCl})$. The formed pellets were reconstituted with lipolyzing solution which contain $50 \%$ glycerol, $11 \%$ skim milk and $39 \%$ MRS broth ( $\mathrm{v} / \mathrm{v})$ as a cryoprotectant and stored at $-21^{\circ} \mathrm{C}$ until further use. Hence, five starter cultures strains used for the fermented sausages with their assigned codes were Starterkulturen Almi Rohschinken, KCTC-3802, KCTC-3598, KCTC-5053, and KCTC-3603. The intended suspension incorporated in the sausage batter was one $\mathrm{mL} / \mathrm{kg}(\mathrm{v} / \mathrm{w})$, and each starting culture had about 6 log colony forming unit (CFU)/g. A hemocytometer (Marienfeld-Superior; Paul Marienfeld $\mathrm{GmbH}$ \& Co. KG, Lauda-Königshofen, Germany) with a computer magnification system was used to count viable cells in the starter culture suspensions.

\section{Manufacturing of dry fermented sausages}

Pork loins were purchased from a local abattoir from the Gyeongsan market, $24 \mathrm{~h}$ post slaughter. Chilled lean pork meat and belly fat was cut and chopped by using a meat mincer (M-12S; Hankook Fujee Industries Co., Ltd., Suwon, Korea) after the removal of visible fat and connective tissue from the lean pork meat. The basic sausage mixture was prepared using ground lean pork meat (73\%), pork belly $(21 \%)$, water $(12 \%)$, salt $(2 \%)$, sodium ascorbate $(0.4 \%)$, sugar $(0.75 \%)$, glucose $(0.85 \%)$, and spices $(0.20 \%)$. All the ingredients and additives were mixed thoroughly using a rotary food mixer (Spar Food Machinery MFG Co., Ltd., Taichung City, Taiwan). The batter was divided into five batches ( $3 \mathrm{~kg}$ each), four for the $L$. sakei strains and one for the commercial starter culture $\left(10^{6} \mathrm{CFU} / \mathrm{g}\right)$. These were added randomly to the divided meat batches accordingly. The batches were named as follows: Control (Starterkulturen Almi Rohschinken, commercial starter culture) (C), KCTC-3802 (S1), KCTC3598 (S2), KCTC-5053 (S3), and KCTC-3603 (S4). The meat batters were stuffed into $50-\mathrm{mm}$ diameter collagen casings (IKJIN Co., Ltd., Seoul, Korea) with a vacuum filling machine (RVF 327; Düker-REX Fleischereimaschinen $\mathrm{GmbH}$, Laufach, Germany). The five batches were manufactured with the same ingredients, formulation, and technology at the same time. The fermentation of sausages was performed in a chamber (SMK-2000SL; Metatek, Suwon, Korea) for seven days at $23^{\circ} \mathrm{C}$ with relative humidity $(\mathrm{RH})$ of $90 \%$ to $95 \%$. The ripening period (14 21 days) following fermentation was carried out at $15^{\circ} \mathrm{C}$ with $\mathrm{RH}$ ranging from $70 \%$ to $75 \%$. The samples were collected from each batch at 7, 14, and 21 days, and physicochemical and microbiological analyses were performed.

\section{Microbiological analysis}

Samples (10 g) from each batch were homogenized in 90-mL saline water $(8.5 \mathrm{~g} / \mathrm{L} \mathrm{NaCl})$ using a Stomacher Lab Blender (model 400 Circulator; Seward Laboratory Systems, New York, NY, USA) for 3 min. Decimal dilutions were prepared to carry out the following analyses: (i) Total viable count (TVC) in plate count agar at $30^{\circ} \mathrm{C}$ for $48 \mathrm{~h}$; and (ii) LAB in MRS at $30^{\circ} \mathrm{C}$ for $48 \mathrm{~h}$. The average numbers of colonies per countable plate were counted 
and $\mathrm{CFU} / \mathrm{g}$ were determined.

\section{Determination of $\mathrm{pH}$}

To measure the $\mathrm{pH}$ value, $3 \mathrm{~g}$ from each fermented sausage treatment was homogenized with $30 \mathrm{~mL}$ distilled water for 10 to $15 \mathrm{~s}$, and $\mathrm{pH}$ was measured by a digital $\mathrm{pH}$ meter (Mettler Toledo, Columbus, OH, USA).

\section{Water activity \\ Water activity $\left(\mathrm{a}_{\mathrm{w}}\right)$ of sausages was examined by direct reading on the water activity measuring meter (Lab Mas- ter- $a_{w}$, Aqualab CX-2; Novasina, Lachen, Switzerland) at $25^{\circ} \mathrm{C}$ using $3 \mathrm{~g}$ of finely chopped fermented sausage sam- ples. All described analyses were performed in the tripli- cate.}

\section{Salinity analysis}

The salinity percentage was determined using salinity meter (Eutech Salt 6+; Thermo Fisher Scientific, Waltham, MA, USA) after homogenizing $3 \mathrm{~g}$ of a ground sample with $15-\mathrm{mL}$ distilled water.

Thiobarbituric acid reactive substances (TBARS) analysis Analysis of lipid oxidation was performed by analyzing the TBARS (Pikul et al., 1989). The fermented sausage sample $(5 \mathrm{~g})$ was homogenized with $50 \mu \mathrm{L}$ of BHA $(7.2 \%$ in ethanol) and $15 \mathrm{~mL}$ of distilled water and then centrifuged at 2,000 rpm for 15 min using a centrifuge (Hanil Science Industrial Co., Ltd., Incheon, Korea). The supernatant $(2 \mathrm{~mL})$ was mixed with $4 \mathrm{~mL}$ thiobarbituric acid (TBA) solution (20 mM TBA in $15 \%$ trichloroacetic acid) followed by heating in a water bath at $90^{\circ} \mathrm{C}$ for $30 \mathrm{~min}$ and then cooling to room temperature. Therefore, TBARS were extracted from cooled samples. The absorbance of each sample was measured at $532 \mathrm{~nm}$ using a spectrophotometer (Multiskan GO; Thermo Fisher Scientific). TBARS, mg malondialdehyde (MDA)/kg sausage was calculated by multiplying the optical density of the reading with a $\mathrm{K}$ factor of 5.2.

\section{Determination of color}

Color of the sausages was determined using a chromameter (CR 300; Minolta Co., Tokyo, Japan), and expressed as L* (lightness), a* (redness), and $\mathrm{b}^{*}$ (yellowness) according to the Commission Internationale de 1'Eclairage lab system. Prior to each analysis session, the chromameter was calibrated using the manufacturer supplied white calibration tile. For each analyzed sausage, color was measured on the interior side of the sausages after removal of the casing. For each trait, the average values were calculated from three replications of randomly measured readings.

\section{Texture profile analysis (TPA)}

TPA for the sausage samples was performed using TPA analyzer (TA 1; Lloyd Instruments, Largo, FL, USA). Four cubic shapes (1-cm long, $1-\mathrm{cm}$ thick, and $1-\mathrm{cm}$ wide) from each dry fermented sausage were subjected to the analysis. A double compression cycle test was performed up to $70 \%$ compression of the original portion. A time of $2 \mathrm{~s}$ could elapse between the two compression cycles. Force-time deformation curves were obtained with a $1 \mathrm{~N}$ load cell applied at a crosshead speed of $2 \mathrm{~mm} / \mathrm{s}$. The following parameters were quantified: hardness (kgf), maximum force required to compress the sample; springiness $(\mathrm{m})$, ability of the sample to recover its original form after deforming force was removed; cohesiveness, extent to which the sample could be deformed prior to rupture; and chewiness (kgf), work required to masticate the sample before swallowing.

\section{Volatile basic nitrogen (VBN) analysis}

Measurements of the VBN content of samples were determined using the Conway micro diffusion method (Conway, 1950). Two Conway's tools per each sample were used after cleaning with a neutral detergent. A sealing agent (Vaseline) was applied to the edge of the outer ring of each unit. Sample $(3 \mathrm{~g})$ was homogenized with $30 \mathrm{~mL}$ of distilled water at $1,000 \mathrm{rpm}$ for $1 \mathrm{~min}$ using a homogenizer. The homogenate was filtered using Whatman \#1 filter paper (GE Healthcare Life Sci., Pittsburg, PA, USA). The filtrate ( $1 \mathrm{~mL}$ ) was pipetted to the outer chamber of a Conway micro diffusion unit, and $1 \mathrm{~mL}$ of $0.01 \mathrm{~N}$ boric acid $\left(\mathrm{H}_{3} \mathrm{BO}_{3}\right)$ and $100 \mu \mathrm{L}$ of Conway indicator $(0.066 \%$ bromocresol green : $0.066 \%$ methyl red, 1:1) were pipetted to the inner chamber. Then, $1 \mathrm{~mL} \mathrm{50 \%}$ potassium carbonate $\left(\mathrm{K}_{2} \mathrm{CO}_{3}\right)$ was added to the outer chamber of the Conway unit and sealed immediately. Incubation was then performed for $2 \mathrm{~h}$ at $37^{\circ} \mathrm{C}$. After the addition of $0.02 \mathrm{~N}$ sulfuric acid $\left(\mathrm{H}_{2} \mathrm{SO}_{4}\right)$ to the inner chamber of the Conway unit, the VBN contents were measured. Total VBN values were expressed in $\mathrm{mg} \%$.

\section{Statistical analysis}

The experimental data was analyzed via a one-way ANOVA using SAS software version 9.4 (SAS Institute, Cary, NC, USA). A significance level of $(P<0.05)$ was used for all examinations. Differences among the means were compared by Duncan's multiple range test.

\section{RESULTS AND DISCUSSION}

The microorganisms with the greatest impact on spoilage of meat products packed in aerobic conditions are usually Pseudomonadaceae and Enterobacteriaceae. When adequately cooked before consumption, they can be a 
source of cross-contamination during meal preparation. LAB, Brochothrix thermosphacta and L. sakei have been reported to successfully inhibit spoilage bacteria in ground meat and sausages (Chaillou et al., 2005; Zagorec and Champomier-Vergès, 2017). Statistical analysis showed a significant difference $(P<0.05)$ on TVC between control and inoculated L. sakei strain sausages. Initial (7th day) TVC counts in inoculated batches were higher (except for S1) than those in the control batch $7.86<8.27<$ $8.34 \log$ CFU/g for S4, S3, and S2, respectively (Table 1). At the end of the fermentation phase, TVC was significantly lower in control sausages $(P<0.05)$ while S2 had the highest value. The use of $L$. sakei starter culture strains to produce sausages significantly affected the amount of TVC as a decline was observed in inoculated sausages as the ripening process increased. Batches inoculated with L. sakei starter culture strains (S2 and S3) showed higher values for total plate count among other treatments on day 14 of the ripening process. TVC decreased about 1.53, 1.06, 0.88 and $0.42 \log$ CFU/g in L. sakei fermented sausages of S3, S2, S1 and S4, respectively, from initial to final values. TVC values greater than $8 \log \mathrm{CFU} / \mathrm{g}$, according to Lamkey et al. (1991), indicated that the meat was in the spoilage stage due to microbial activity. The total plate count of all the treatments in this study did not exceed the stated value.

The Lactobacillus spp. counts, monitored throughout the study period, rapidly increased from the initial range of $7.47 \log \mathrm{CFU} / \mathrm{g}$ to $8.30 \log \mathrm{CFU} / \mathrm{g}$ on day 7 and then significantly $(P<0.05)$ decreased to 6.18 to $7.25 \log \mathrm{CFU} / \mathrm{g}$ on day 21 (end of ripening) (Table 1). The maximum LAB level was observed on the day 7 (end of fermentation) and then a slight decrease was observed at the end of ripening. This slight decrease of $\mathrm{LAB}$ during ripening might be due to reduction in water activity and fermentable carbohydrates (Lorenzo and Franco, 2012). A higher value of LAB count was observed in S2 as compared to other $L$. sakei inoculated treatments throughout the ripening period (14 to 21 days). Final products can be ordered from highest to the lowest on the bases of their LAB count as follow: S2 > S4> S1 with the corresponding values of 7.25, 7.17, and $6.48 \log \mathrm{CFU} / \mathrm{g}$, respectively. These outcomes agree with those reported by Baka et al. (2011). LAB counts, which have an important role for the formation of characteristic acidic taste and flavor of sausage, considerably increased during fermentation. LAB became the dominating bacterium as expected due to their good adaption to the meat environment and quicker growth rates throughout fermentation and sausage ripening (Essid and Hassouna, 2013). The lowered pH, lactic acid and other metabolites are generated to inhibit growth of other microorganism groups, including molds, during the fermentation of sausages (Bacha et al., 2010).

Values corresponding to $\mathrm{pH}$, water activity and salinity throughout study period are summarized in Table 2 . The presence of $L$. sakei led to acidification of the samples probably boosted by the added dextrose. The $\mathrm{pH}$ decrease inhibits undesirable microorganisms, accelerates the reduction of nitrite to nitric oxide, affects the flavor of the product, and facilitates meat binding capacity to improve firmness and slice ability (Varnam and Sutherland 1995; Lücke, 1998), all of which contribute to the safety and quality of the sausages. As shown in Table 2, lower $\mathrm{pH}$ values as compared to other treatments were exhibited in S3 and S4 having similar value of 4.67 at the end of fermentation (day 7). The $\mathrm{pH}$ for S2 had a lower value of 4.68 as compared to other $L$. sakei inoculated sausages during the ripening period (day 14). However, the different strains of $L$. sakei starter cultures did not have a substantial difference $(P>0.05)$ in $\mathrm{pH}$ values for the fermented sausages at the end of the ripening process. Our study showed that inoculated sausages had lower $\mathrm{pH}$ values ranging from 4.72 to 4.79 than the control (4.81) on day 21. After fermentation, the $\mathrm{pH}$ values significantly $(P<$

Table 1. Total viable count (TVC) and lactic acid bacteria (LAB) of dry fermented sausage inoculated with different strains of Lactobacillus sakei starter cultures during fermentation and ripening (unit: $\log \mathrm{CFU} / \mathrm{g}$ )

\begin{tabular}{|c|c|c|c|c|c|c|c|}
\hline \multirow{2}{*}{ Parameter } & \multirow{2}{*}{ Day } & \multicolumn{5}{|c|}{ Treatment } & \multirow{2}{*}{ SEM } \\
\hline & & C & S1 & $\mathrm{S} 2$ & S3 & S4 & \\
\hline \multirow[t]{4}{*}{ TVC } & 7 & $7.56^{\mathrm{abA}}$ & $7.18^{\mathrm{bA}}$ & $8.34^{\mathrm{aA}}$ & $8.27^{\mathrm{aA}}$ & $7.86^{\mathrm{abA}}$ & 0.48 \\
\hline & 14 & $7.69^{\mathrm{aA}}$ & $6.27^{\mathrm{cB}}$ & $7.52^{\mathrm{abB}}$ & $7.62^{\mathrm{abA}}$ & $7.25^{\mathrm{bB}}$ & 0.23 \\
\hline & 21 & $5.90^{\mathrm{dB}}$ & $6.30^{\mathrm{cA}}$ & $7.28^{\mathrm{aB}}$ & $6.74^{\mathrm{bB}}$ & $7.44^{\mathrm{aAB}}$ & 0.13 \\
\hline & SEM & 0.40 & 0.39 & 0.20 & 0.38 & 0.27 & \\
\hline \multirow[t]{4}{*}{ LAB } & 7 & $8.30^{\mathrm{aA}}$ & $7.85^{\mathrm{abA}}$ & $8.12^{\mathrm{abA}}$ & $7.76^{\mathrm{abA}}$ & $7.47^{\mathrm{bA}}$ & 0.41 \\
\hline & 14 & $7.78^{\mathrm{aB}}$ & $6.32^{\mathrm{bB}}$ & $7.11^{\mathrm{aB}}$ & $6.24^{\mathrm{bB}}$ & $5.99^{\mathrm{bB}}$ & 0.38 \\
\hline & 21 & $6.18^{\mathrm{cC}}$ & $6.48^{\mathrm{bB}}$ & $7.25^{\mathrm{aB}}$ & $6.21^{\mathrm{cB}}$ & $7.17^{\mathrm{aA}}$ & 0.05 \\
\hline & SEM & 0.23 & 0.49 & 0.25 & 0.36 & 0.18 & \\
\hline
\end{tabular}

Treatments are different strain of $L$. sakei starter culture used in this study: C, commercial starter culture control; S1, L. sakei Korean Collection for Type Cultures (KCTC)-3802; S2, L. sakei KCTC-3598; S3, L. sakei KCTC-5053; S4, L. sakei KCTC-3603; SEM, standard error of mean; CFU, colony forming unit.

Different letters (a-d) within a row are significantly different at $P<0.05(n=3)$. Different letters $(A-C)$ within a column of the different storage days are significantly different $(P<0.05)$. 
Table 2. Effect of different strains of Lactobacillus sakei starter cultures on $\mathrm{pH}$, water activity ( $\left.\mathrm{a}_{w}\right)$, and salinity of dry fermented sausages during fermentation and ripening

\begin{tabular}{|c|c|c|c|c|c|c|c|}
\hline \multirow{2}{*}{ Parameter } & \multirow{2}{*}{ Day } & \multicolumn{5}{|c|}{ Treatment } & \multirow{2}{*}{ SEM } \\
\hline & & C & S1 & S2 & S3 & S4 & \\
\hline \multirow[t]{4}{*}{$\mathrm{pH}$} & 7 & $4.70^{\mathrm{aB}}$ & $4.70^{\mathrm{aB}}$ & $4.71^{\mathrm{aB}}$ & $4.67^{\mathrm{bC}}$ & $4.67^{\mathrm{bB}}$ & 0.00 \\
\hline & 14 & $4.72^{\mathrm{B}}$ & $4.73^{\mathrm{A}}$ & $4.68^{\mathrm{bC}}$ & $4.74^{\mathrm{B}}$ & $4.74^{\mathrm{aA}}$ & 0.01 \\
\hline & 21 & $4.81^{\mathrm{aA}}$ & $4.72^{\mathrm{cA}}$ & $4.74^{\mathrm{CA}}$ & $4.79^{\mathrm{bA}}$ & $4.75^{\mathrm{cA}}$ & 0.00 \\
\hline & SEM & 0.01 & 0.01 & 0.01 & 0.01 & 0.01 & \\
\hline \multirow{4}{*}{$a_{w}$} & 7 & $0.91^{\mathrm{aA}}$ & $0.90^{\mathrm{bA}}$ & $0.91^{\mathrm{aA}}$ & $0.91^{\mathrm{aA}}$ & $0.91^{\mathrm{aA}}$ & 0.00 \\
\hline & 14 & $0.83^{\mathrm{cB}}$ & $0.90^{\mathrm{aA}}$ & $0.80^{\mathrm{eB}}$ & $0.82^{\mathrm{dB}}$ & $0.88^{\mathrm{bB}}$ & 0.00 \\
\hline & 21 & $0.80^{a C}$ & $0.80^{\mathrm{aB}}$ & $0.78^{\mathrm{aC}}$ & $0.79^{a b C}$ & $0.78^{\mathrm{bC}}$ & 0.01 \\
\hline & SEM & 1.07 & 0.00 & 0.00 & 0.00 & 0.01 & \\
\hline \multirow[t]{4}{*}{ Salinity (\%) } & 7 & $5.10^{a c}$ & $4.73^{\mathrm{dB}}$ & $4.83^{\mathrm{cC}}$ & $4.67^{\mathrm{eC}}$ & $4.92^{\mathrm{bC}}$ & 0.01 \\
\hline & 14 & $6.03^{\mathrm{aA}}$ & $4.72^{\mathrm{bB}}$ & $6.14^{\mathrm{aB}}$ & $6.13^{\mathrm{aB}}$ & $5.58^{\mathrm{aB}}$ & 0.60 \\
\hline & 21 & $5.76^{\mathrm{eB}}$ & $6.32^{\mathrm{cA}}$ & $6.16^{\mathrm{dA}}$ & $6.44^{\mathrm{aA}}$ & $6.39^{\mathrm{bA}}$ & 0.01 \\
\hline & SEM & 0.01 & 0.77 & 0.01 & 0.01 & 0.01 & \\
\hline
\end{tabular}

Treatments are different strain of $L$. sakei starter culture used in this study: $C$, commercial starter culture control; S1, L. sakei Korean Collection for Type Cultures (KCTC)-3802; S2, L. sakei KCTC-3598; S3, L. sakei KCTC-5053; S4, L. sakei KCTC-3603; SEM, standard error of mean.

Different letters $(\mathrm{a}-\mathrm{e})$ within a row are significantly different $(P<0.05)$. Different letters $(\mathrm{A}-\mathrm{C})$ within a column of the different storage days are significantly different $(P<0.05)$.

0.05) increased in control and inoculated fermented sausages until the end of the ripening period. The rise in $\mathrm{pH}$ during the final stages of ripening could be attributed to proteolytic activity produced by microorganisms. Proteolytic breakdown by bacterial proteases produces peptides, amino acids, and amines, which act as buffers for the organic acids produced by LAB during fermentation (RuizMoyano et al., 2011).

Cured meats such as ham, fermented meats such as sausage and pepperoni, and dried meats such as jerky are examples of meat products that use water activity to increase shelf-stability. Most meat products with lower $a_{w}$ levels, use salt to bind water and drying techniques to reduce the total moisture content, as a result, the product's $a_{w}$ decreases. The $a_{w}$ of $L$. sakei inoculated fermented sausages significantly decreased throughout the ripening process ranging from 0.91 to 0.78 (Table 2). After 7 days of fermentation in sausages fermented by L. sakei, a notable decline was observed in C, S2, S3, and S4. At the end of the ripening process, $a_{w}$ values have no significant difference $(P>0.05)$ for inoculated and non-inoculated treatments. Our conclusions concur with previous reports of studies, in which the $a_{w}$ value of treatments with various starter cultures during their maturation did not differ significantly (Chen et al., 2021). At day 21, all treatments were considered acceptable for food quality, as they were lower than the maximum value of 0.95 (Papadima and Bloukas, 1999). In terms of food safety, a lower $a_{w}$ is considered better to inhibit the growth of pathogenic and spoilage bacteria. The statistical analysis revealed no significant difference $(P>0.05)$ between the inoculated and control sausages at the end of ripening process. This finding contradicts the findings of Kaban and Kaya (2009), who discovered that samples with starter culture had lower levels of $a_{w}$ values as compared to the control. Thus, inoculation of $L$. sakei into dry fermented sausages can contribute to shelf life extension.

Salt plays a variety of roles in fermented sausages, including flavor, texture, microbiological safety, and overall acceptability. According to Terrell (1983) salt aids in the solubilization of myofibrillar proteins, improves protein binding properties, and increases the viscosity of meat batters. Fermented sausages having a high salt content contributes to the microbiological safety and shelf life of the product by binding water, making it inaccessible to microorganisms. Initially, salt content for dry fermented sausages incorporated with strains of $L$. sakei had low values at day 7 (end of fermentation); however a significant $(P<0.05)$ increase was observed during the ripening period (day 14). Products can be ordered from highest to the lowest on the bases of their salinity as follow: $\mathrm{S} 3>\mathrm{S} 4>\mathrm{S} 1>\mathrm{S} 2>\mathrm{C}$ with the corresponding values of $6.44 \%, 6.39 \%, 6.32 \%, 6.16 \%$, and $5.76 \%$, respectively. Typically, the average salt content in fermented sausage stuffing ranges from $2.0 \%$ to $2.6 \%$, and due to water loss during drying, this proportion in the finished product falls to $3.3 \%$ to $5.5 \%$ (Kovačević et al., 2014).

MDA is formed as result of lipid oxidation which causes off-flavor of oxidized fat. The outcomes of lipid oxidation are quality deterioration (rancid odor, off-flavor, drip losses, discoloration, nutrient loss, and shelf life reduction) and also serious health risks (Chaijan, 2008; Mapiye et al., 2012). During the ripening process (day $14)$, treatments inoculated with different strains of LAB starter cultures showed a significant difference $(P<0.05)$ in TBARS content (Table 3), in the following order: S4> 
Table 3. Effect of different strains of Lactobacillus sakei starter cultures on thiobarbituric acid reactive substances (TBARS) and volatile basic nitrogen (VBN) values of dry fermented sausages during fermentation and ripening

\begin{tabular}{|c|c|c|c|c|c|c|c|}
\hline \multirow{2}{*}{ Parameter } & \multirow{2}{*}{ Day } & \multicolumn{5}{|c|}{ Treatment } & \multirow{2}{*}{ SEM } \\
\hline & & C & $\mathrm{S} 1$ & $\mathrm{~S} 2$ & S3 & S4 & \\
\hline \multirow[t]{4}{*}{ TBARS (mgMDA/kg) } & 7 & $0.90^{\mathrm{dA}}$ & $1.14^{\mathrm{bA}}$ & $0.77^{\mathrm{eB}}$ & $1.01^{\mathrm{cA}}$ & $1.18^{\mathrm{aA}}$ & 0.00 \\
\hline & 14 & $0.64^{\mathrm{eB}}$ & $0.74^{\mathrm{cB}}$ & $0.88^{\mathrm{bA}}$ & $0.66^{\mathrm{dB}}$ & $0.95^{\mathrm{aB}}$ & 0.00 \\
\hline & SEM & 0.00 & 0.01 & 0.00 & 0.01 & 0.00 & \\
\hline & 7 & $5.69^{\mathrm{abB}}$ & $5.60^{\mathrm{abB}}$ & $5.97^{\mathrm{aB}}$ & $5.60^{\mathrm{abB}}$ & $5.32^{\mathrm{bB}}$ & 0.23 \\
\hline \multirow{2}{*}{ VBN (mg\%) } & 14 & $12.88^{\mathrm{aA}}$ & $7.00^{\mathrm{CA}}$ & $6.91^{\mathrm{cA}}$ & $8.31^{\mathrm{bA}}$ & $8.40^{\mathrm{bA}}$ & 0.16 \\
\hline & SEM & 0.22 & 0.00 & 0.32 & 0.11 & 0.19 & \\
\hline
\end{tabular}

Treatments are different strain of $L$. sakei starter culture used in this study: C, commercial starter culture control; S1, L. sakei Korean Collection for Type Cultures (KCTC)-3802; S2, L. sakei KCTC-3598; S3, L. sakei KCTC-5053; S4, L. sakei KCTC-3603; SEM, standard error of mean; MDA, malondialdehyde.

Different letters $(\mathrm{a}-\mathrm{e})$ within a row are significantly different $(P<0.05)$. Different letters $(\mathrm{A}, \mathrm{B})$ within a column of the different storage days are significantly different $(P<0.05)$.

S2> S1> S3. The lowest treatment was the S3 L. sakei inoculated fermented sausage at $0.66 \mathrm{mg} \mathrm{MDA} / \mathrm{kg}$ followed by the control. According to Munekata et al. (2020), the possibility for the decrease in TBARS can be associated to shorter service life, and to the presence of antioxidants and spices in the recipe, which prevent lipid oxidation. Fermented sausages with TBARS in the range of 0.6 to $2.8 \mathrm{mg} \mathrm{MDA} / \mathrm{kg}$ are acceptable (Marco et al., 2006). The TBARS values for all treatments in this study did not exceed the stated range.

The VBN value represents the total growth of aerobic bacteria in meat products (Jung et al., 2010). Bio-protective cultures, which inhibited the spoilage bacteria, were able to reduce the total VBN values below $30 \mathrm{mg}$ nitrogen/100 g (Comi et al., 2015). During the ripening period, the value of VBN significantly $(P<0.05)$ increased for inoculated fermented sausages and control, and these findings agree with Egan et al. (1981) who observed that accelerated protein degradation explains a higher VBN in sausages. The VBN values (Table 3 ) of the $L$. sakei treated samples was significantly $(P<0.05)$ lower than that of the control at the end of the maturity period (day 14), the values ranged from $6.91 \mathrm{mg} \%$ to $12.88 \mathrm{mg} \%$. The lower value of $6.91 \mathrm{mg} \%$ was observed for the S2 treated sample during ripening. VBN values ranging from 7 to 18 $\mathrm{mg} \%$ was reported by Lin and Lin (2002) in Chinese style dry-cured sausage during the ripening period.

The color traits lightness, redness, and yellowness of fermented sausages during the study period are presented in Table 4. Color changes, and particularly red dis-coloration, are physiological at the end of the shelf-life of sausages (Nuvoloni et al., 2012). Statistical analysis displayed that instrumental color of fermented sausages was significantly $(P<0.05)$ affected by the ripening time and the use of $L$. sakei starter culture strains. These outcomes agree with those reported by Essid and Hassouna (2013).

Table 4. Effect of different strains of Lactobacillus sakei starter cultures on color values of dry fermented sausages during fermentation and ripening

\begin{tabular}{|c|c|c|c|c|c|c|c|}
\hline \multirow{2}{*}{ Parameter } & \multirow{2}{*}{ Day } & \multicolumn{5}{|c|}{ Treatment } & \multirow{2}{*}{ SEM } \\
\hline & & C & S1 & $\mathrm{S} 2$ & S3 & S4 & \\
\hline \multirow[t]{4}{*}{ L* (lightness) } & 7 & $58.7^{\mathrm{bAB}}$ & $60.7^{\mathrm{bA}}$ & $61.9^{\mathrm{abA}}$ & $65.2^{\mathrm{aA}}$ & $65.3^{\mathrm{aA}}$ & 2.45 \\
\hline & 14 & $60.4^{\mathrm{A}}$ & $58.04^{\mathrm{A}}$ & $61.8^{\mathrm{A}}$ & $62.3^{\mathrm{B}}$ & $59.8^{\mathrm{B}}$ & 2.95 \\
\hline & 21 & $54.2^{\mathrm{abB}}$ & $54.1^{\mathrm{bB}}$ & $56.0^{\mathrm{abB}}$ & $54.2^{\mathrm{abc}}$ & $57.6^{\mathrm{aB}}$ & 2.38 \\
\hline & SEM & 3.27 & 2.58 & 2.34 & 1.81 & 2.79 & \\
\hline \multirow[t]{4}{*}{ a* (redness) } & 7 & 8.45 & $8.95^{\mathrm{A}}$ & 8.62 & 7.42 & $7.31^{\mathrm{AB}}$ & 1.3 \\
\hline & 14 & 7.11 & $8.23^{\mathrm{AB}}$ & 7.23 & 7.83 & $8.44^{\mathrm{A}}$ & 1.12 \\
\hline & 21 & $7.37^{\mathrm{ab}}$ & $6.57^{\mathrm{bB}}$ & $8.00^{\mathrm{ab}}$ & $8.37^{\mathrm{a}}$ & $6.45^{\mathrm{bB}}$ & 1.18 \\
\hline & SEM & 2.53 & 1.22 & 1.33 & 0.93 & 1.05 & \\
\hline \multirow[t]{4}{*}{ b* (yellowness) } & 7 & $7.14^{\mathrm{bB}}$ & $7.50^{\mathrm{ab}}$ & $7.87^{\mathrm{ab}}$ & $8.37^{\mathrm{a}}$ & $8.33^{\mathrm{a}}$ & 0.64 \\
\hline & 14 & $8.82^{\mathrm{A}}$ & 8.31 & 8.2 & 8.62 & 8.08 & 0.75 \\
\hline & 21 & $8.43^{\mathrm{A}}$ & 8.74 & 8.56 & 9.44 & 7.95 & 1.07 \\
\hline & SEM & 0.61 & 0.96 & 0.67 & 0.94 & 0.97 & \\
\hline
\end{tabular}

Treatments are different strain of L. sakei starter culture used in this study: C, commercial starter culture control; S1, L. sakei Korean Collection for Type Cultures (KCTC)-3802; S2, L. sakei KCTC-3598; S3, L. sakei KCTC-5053; S4, L. sakei KCTC-3603; SEM, standard error of mean.

Different letters $(a, b)$ within a row are significantly different $(P<0.05)$. Different letters $(A, B)$ within a column of the different storage days are significantly different $(P<0.05)$. 
S3 and S4 have the highest value of $\mathrm{L}^{*}$ during fermentation but reduction in the lightness was observed in S2, S3, and S4 at day14. At the end of ripening, treatments S4 and S2 exhibited a higher value of $L^{*}$, whereas the lowest $\mathrm{L}^{*}$ values of sausages were in batches inoculated with S1 starter cultures and overall, no significant difference $(P>0.05)$ was observed between the inoculated and control sausages. Red intensity is the most sensitive parameter for measuring color, characterization of red color, and color stability (García-Esteban et al., 2003). The formation of nitrosyl-myoglobin by the reaction of nitrogen monoxide with myoglobin is clearly responsible for the increase in redness. After fermentation (day 7) and to the end of ripening (day 21), the redness significantly $(P<0.05)$ decreased in all treatments except for S3, as redness value increased from 7.42 to 8.37 at the end of ripening. The reduction in $\mathrm{a}^{*}$ in these treatments is most likely due to reduction in Microccaeceae count. Micrococcaceae can generate catalase, an enzyme that degrades the hydrogen peroxide $\left(\mathrm{H}_{2} \mathrm{O}_{2}\right)$ produced by LAB. The heme pigments in sausages are attacked by $\mathrm{H}_{2} \mathrm{O}_{2}$, resulting in oxidative discoloration. The elevated $\mathrm{b}^{*}$ values were observed in treated batches in the following order S3> $\mathrm{S} 1>\mathrm{S} 2>\mathrm{C}$ throughout ripening, but the sample inoculated with $\mathrm{S} 4$ showed a decrease in yellowness during this period (14 to 21 days), which is most likely due to oxygen consumption by microorganisms during their exponential growth phase and a decrease in oxymyoglobin. Eventually for yellowness, no significant $(P>0.05)$ differences were observed between the control and all $L$. sakei starter culture inoculated sausages.

TPA for the control and starter-inoculated sausages are reported in Table 5. Addition of different strains of $L$. sakei starter cultures did not affect the TPA trait of springiness across the study period; however, substantial differences $(P<0.05)$ were observed in hardness, cohesiveness, and chewiness traits of dry fermented sausages in the final products of all treatment samples. The values of hardness were in the following order S2>S1 > S3>S4 but these values were lower as compared to control at the end of maturation. The treatment ranking for springiness was S3, S4>S2, and C>S1. Hardness of the L. sakei inoculated fermented sausages was significantly influenced by the ripening time and increased from the initial mean values 0.82 to $1.03 \mathrm{kgf}$ (day 7) to 1.55 to $2.93 \mathrm{kgf}$ (day 21). A slight increase in springiness was exhibited in all the treatments at the end of ripening, which was maybe due to differences in biochemical processes that have affected the evaporation of water from the products during the drying process. $\mathrm{C}$ and $\mathrm{S} 1$ gave the highest score $(0.15)$ for the cohesiveness trait. The cohesiveness trait significantly decreased $(P<0.05)$ for the treated batches throughout ripening (14 to 21 days) and values were ordered as follows: $\mathrm{C}, \mathrm{S} 1>\mathrm{S} 3$, and S4>S2. The possible reason for this decline may be due to loss in binding and rheological properties of ingredients because of dryness. Similarly, previous studies have shown that both hardness and chewiness increased in low fat dry fermented sausages due to moisture loss during the dry curing process (Salazar et al., 2009). The findings of our study

Table 5. Effect of different strains of Lactobacillus sakei starter cultures on texture profile analysis of dry fermented sausages during fermentation and ripening

\begin{tabular}{|c|c|c|c|c|c|c|c|}
\hline \multirow{2}{*}{ Parameter } & \multirow{2}{*}{ Day } & \multicolumn{5}{|c|}{ Treatment } & \multirow{2}{*}{ SEM } \\
\hline & & C & S1 & $\mathrm{S} 2$ & S3 & S4 & \\
\hline \multirow[t]{4}{*}{ Hardness (kgf) } & 7 & $0.82^{\mathrm{B}}$ & $1.03^{\mathrm{B}}$ & $1.02^{B}$ & $0.92^{\mathrm{B}}$ & 0.87 & 0.13 \\
\hline & 14 & $1.35^{\mathrm{B}}$ & $1.28^{\mathrm{B}}$ & $1.39^{\mathrm{B}}$ & $1.28^{\mathrm{B}}$ & 1.11 & 0.15 \\
\hline & 21 & $2.93^{\mathrm{aA}}$ & $2.21^{\mathrm{abA}}$ & $2.27^{\mathrm{abA}}$ & $1.84^{\mathrm{bA}}$ & $1.55^{\mathrm{b}}$ & 0.51 \\
\hline & SEM & 0.33 & 0.21 & 0.37 & 0.20 & 0.41 & \\
\hline \multirow[t]{4}{*}{ Springiness (m) } & 7 & 0.83 & 0.92 & $0.92^{\mathrm{B}}$ & $0.92^{\mathrm{B}}$ & $0.91^{\mathrm{B}}$ & 0.06 \\
\hline & 14 & $0.84^{\mathrm{b}}$ & $0.94^{\mathrm{a}}$ & $0.94^{\mathrm{aAB}}$ & $0.95^{\mathrm{aAB}}$ & $0.94^{\mathrm{aAB}}$ & 0.04 \\
\hline & 21 & 0.96 & 0.94 & $0.96^{\mathrm{A}}$ & $0.97^{\mathrm{A}}$ & $0.97^{\mathrm{A}}$ & 0.02 \\
\hline & SEM & 0.08 & 0.05 & 0.01 & 0.01 & 0.02 & \\
\hline \multirow[t]{4}{*}{ Cohesiveness } & 7 & $0.30^{\mathrm{A}}$ & $0.32^{\mathrm{A}}$ & $0.31^{\mathrm{A}}$ & $0.27^{\mathrm{A}}$ & $0.28^{A}$ & 0.05 \\
\hline & 14 & $0.23^{\mathrm{AB}}$ & $0.24^{\mathrm{A}}$ & $0.23^{\mathrm{A}}$ & $0.20^{\mathrm{AB}}$ & $0.21^{\mathrm{B}}$ & 0.03 \\
\hline & 21 & $0.15^{\mathrm{aB}}$ & $0.15^{\mathrm{aB}}$ & $0.08^{\mathrm{bB}}$ & $0.12^{\mathrm{abB}}$ & $0.12^{\mathrm{abC}}$ & 0.03 \\
\hline & SEM & 0.04 & 0.04 & 0.04 & 0.05 & 0.02 & \\
\hline \multirow[t]{4}{*}{ Chewiness (kgf) } & 7 & $0.21^{\mathrm{B}}$ & 0.31 & 0.29 & 0.23 & 0.22 & 0.08 \\
\hline & 14 & $0.24^{\mathrm{B}}$ & 0.27 & 0.27 & 0.22 & 0.21 & 0.05 \\
\hline & 21 & $0.44^{\mathrm{aA}}$ & $0.32^{\mathrm{abA}}$ & $0.17^{b}$ & $0.22^{b}$ & $0.18^{\mathrm{b}}$ & 0.09 \\
\hline & SEM & 0.08 & 0.09 & 0.08 & 0.08 & 0.04 & \\
\hline
\end{tabular}

Treatments are different strain of $L$. sakei starter culture used in this study: C, commercial starter culture control; S1, L. sakei Korean Collection for Type Cultures (KCTC)-3802; S2, L. sakei KCTC-3598; S3, L. sakei KCTC-5053; S4, L. sakei KCTC-3603; SEM, standard error of mean.

Different letters $(a, b)$ within a row are significantly different $(P<0.05)$. Different letters $(A-C)$ within a column of the different storage days are significantly different $(P<0.05)$. 
are consistent with those of Essid and Hassouna (2013), who found no significant differences between control and inoculated sausages. However, no significant $(P>0.05)$ differences were observed among the inoculated treatments and control in springiness and adhesiveness profiles during the study period.

In conclusion, different strains of $L$. sakei had a significant influence on LAB, TBARS, and VBN values of dry fermented sausages after the ripening period. The inoculation of L. sakei KCTC-3598 (S2) imparted a beneficial effect on LAB count, and L. sakei KCTC-5053 (S3) was helpful in reduction of lipid oxidation (TBARS) and instrumental color. Hence, these strains would be good candidates for enhancing the quality attributes of dry fermented sausages.

\section{ACKNOWLEDGEMENTS}

This research was supported by Basic Science Research Program through the National Research Foundation of Korea (NRF) grant funded by the Korea government (MSIT) (2017R1A2B201277).

\section{AUTHOR DISCLOSURE STATEMENT}

The authors declare no conflict of interest.

\section{REFERENCES}

Adams MR. Topical aspects of fermented foods. Trends Food Sci Technol. 1990. 1:140-144.

Bacha K, Jonsson $\mathrm{H}$, Ashenafi M. Microbial dynamics during the fermentation of Wakalim, a traditional Ethiopian fermented sausage. J Food Qual. 2010. 33:370-390.

Baka AM, Papavergou EJ, Pragalaki T, Bloukas JG, Kotzekidou P. Effect of selected autochthonous starter cultures on processing and quality characteristics of Greek fermented sausages. LWT. 2011. 44:54-61.

Buckel W. Energy conservation in fermentations of anaerobic bacteria. Front Microbiol. 2021. 12:703525. https://doi.org/ 10.3389/fmicb.2021.703525

Chaijan M. Review: lipid and myoglobin oxidations in muscle foods. Songklanakarin J Sci Technol. 2008. 30:47-53.

Chaillou S, Champomier-Vergès MC, Cornet M, Crutz-Le Coq AM, Dudez AM, Martin V, et al. The complete genome sequence of the meat-borne lactic acid bacterium Lactobacillus sakei 23K. Nat Biotechnol. 2005. 23:1527-1533.

Chen X, Mi R, Qi B, Xiong S, Li J, Qu C, et al. Effect of proteolytic starter culture isolated from Chinese Dong fermented pork (Nanx Wudl) on microbiological, biochemical and organoleptic attributes in dry fermented sausages. Food Sci Hum Wellness. 2021. 10:13-22.

Comi G, Tirloni E, Andyanto D, Manzano M, Iacumin L. Use of bio-protective cultures to improve the shelf-life and the sensorial characteristics of commercial hamburgers. LWT. 2015. 62:1198-1202.

Conway EJ. Microdiffusion analysis and volumetric error. 3rd ed.
Crosby Lockwood \& Son, London, UK. 1950. p 95.

Egan H, Kirk RS, Sawyer R. Pearson's chemical analysis of foods. 8th ed. Churchill Livingstone, Edinburgh, UK. 1981. p 185.

Essid I, Hassouna M. Effect of inoculation of selected Staphylococcus xylosus and Lactobacillus plantarum strains on biochemical, microbiological and textural characteristics of a Tunisian dry fermented sausage. Food Control. 2013. 32:707-714.

Fontana C, Bassi D, López C, Pisacane V, Otero MC, Puglisi E, et al. Microbial ecology involved in the ripening of naturally fermented llama meat sausages. A focus on lactobacilli diversity. Int J Food Microbiol. 2016. 236:17-25.

García-Esteban M, Ansorena D, Gimeno O, Astiasarán I. Optimization of instrumental colour analysis in dry-cured ham. Meat Sci. 2003. 63:287-292.

Gelinski JMLN, Baratto CM, Casagrande M, de Oliveira TP, Megiolaro F, de Martini Soares FAS, et al. Control of pathogens in fresh pork sausage by inclusion of Lactobacillus sakei BAS0117. Can J Microbiol. 2019. 65:831-841.

Hugas M, Monfort JM. Bacterial starter cultures for meat fermentation. Food Chem. 1997. 59:547-554.

Hutkins RW. Meat fermentation. In: Hutkins RW, editor. Microbiology and technology of fermented foods. Blackwell Publishing, Ames, IA, USA. 2006. p 207-232.

Jung S, Choe JH, Kim B, Yun H, Kruk ZA, Jo C. Effect of dietary mixture of gallic acid and linoleic acid on antioxidative potential and quality of breast meat from broilers. Meat Sci. 2010. 86:520-526.

Justo TH, Tussolini L, de Macedo REF, Wolupeck HL, dalla Santa HS, dalla Santa OR. Antimicrobial resistance of Lactobacillus sp. isolated from naturally fermented salami produced in Southern Brazil. Vet Zootec. 2013. 20:285-295.

Kaban G, Kaya M. Effects of Lactobacillus plantarum and Staphylococcus xylosus on the quality characteristics of dry fermented sausage "sucuk". J Food Sci. 2009. 74:S58-S63.

Katagiri H, Kitahara K, Fukami K, Sugase M. The characteristics of the lactic acid bacteria isolated from moto, yeast mashes for Saké manufacture. Bull Agric Chem Soc Japan. 1934. 10:153157.

Kovačević D, Mastanjević K, Frece J, Pleadin J, Šakić I. Effect of addition of various sugars on fermentation process of Croatian indigenous dry sausage Kulenova seka. Meso. 2014. 16:351355.

Lamkey JW, Leak FW, Tuley WB, Johnson DD, West RL. Assessment of sodium lactate addition to fresh pork sausage. J Food Sci. 1991. 56:220-223.

Leroy F, Geyzen A, Janssens M, De Vuyst L, Scholliers P. Meat fermentation at the crossroads of innovation and tradition: a historical outlook. Trends Food Sci Technol. 2013. 31:130-137.

Leroy F, Verluyten J, De Vuyst L. Functional meat starter cultures for improved sausage fermentation. Int J Food Microbiol. 2006. 106:270-285.

Lin KW, Lin SN. Effects of sodium lactate and trisodium phosphate on the physicochemical properties and shelf life of lowfat Chinese-style sausage. Meat Sci. 2002. 60:147-154.

Lorenzo JM, Franco D. Fat effect on physico-chemical, microbial and textural changes through the manufactured of dry-cured foal sausage lipolysis, proteolysis and sensory properties. Meat Sci. 2012. 92:704-714.

Lücke FK. Fermented sausages. In: Wood BJB, editor. Microbiology of fermented foods. Springer, Boston, MA, USA. 1998. p 441-483.

Mapiye C, Aldai N, Turner TD, Aalhus JL, Rolland DC, Kramer $\mathrm{JK}$, et al. The labile lipid fraction of meat: from perceived disease and waste to health and opportunity. Meat Sci. 2012. 92: 210-220.

Marco A, Navarro JL, Flores M. The influence of nitrite and nitrate on microbial, chemical and sensory parameters of slow dry fer- 
mented sausage. Meat Sci. 2006. 73:660-673.

Munekata PES, Rocchetti G, Pateiro M, Lucini L, Domínguez R, Lorenzo JM. Addition of plant extracts to meat and meat products to extend shelf-life and health-promoting attributes: an overview. Curr Opin Food Sci. 2020. 31:81-87.

Nastasijevic I, Mitrovic R, Buncic S. The occurrence of Escherichia coli $\mathrm{O} 157 \mathrm{in} /$ on faeces, carcasses and fresh meats from cattle. Meat Sci. 2009. 82:101-105.

Nguyen HT, Elegado FB, Librojo-Basilio NT, Mabesa RC, Dizon EI. Isolation and characterisation of selected lactic acid bacteria for improved processing of Nem chua, a traditional fermented meat from Vietnam. Benef Microbes. 2010. 1:67-74.

Nuvoloni R, Pedonese F, Fratini F, Torracca B, Turchi B, Serra A, et al. Microbiological and physicochemical profile of traditional Salsicda toscana during storage. Ital J Anim Sci. 2012. 11:e59. https://doi.org/10.4081/ijas.2012.e59

Papadima SN, Bloukas JG. Effect of fat level and storage conditions on quality characteristics of traditional Greek sausages. Meat Sci. 1999. 51:103-113.

Parvez S, Malik KA, Kang SA, Kim HY. Probiotics and their fermented food products are beneficial for health. J Appl Microbiol. 2006. 100:1171-1185.

Pikul J, Leszczynski DE, Kummerow FA. Evaluation of three modified TBA methods for measuring lipid oxidation in chicken meat. J Agric Food Chem. 1989. 37:1309-1313.

Pilevar Z, Hosseini H. Effects of starter cultures on the properties of meat products: a review. Annu Res Rev Biol. 2017. 17:1-17.
Ruiz-Moyano S, Martín A, Benito MJ, Hernández A, Casquete R, de Guia Córdoba M. Application of Lactobacillus fermentum HL57 and Pediococcus acidilactici SP979 as potential probiotics in the manufacture of traditional Iberian dry-fermented sausages. Food Microbiol. 2011. 28:839-847.

Salazar P, García ML, Selgas MD. Short-chain fructooligosaccharides as potential functional ingredient in dry fermented sausages with different fat levels. Int J Food Sci Technol. 2009. 44: 1100-1107.

Tamang JP, Watanabe K, Holzapfel WH. Review: diversity of microorganisms in global fermented foods and beverages. Front Microbiol. 2016. 7:377. https://doi.org/10.3389/fmicb.2016. 00377

Terrell RN. Reducing the sodium content of processed meats. Food Technol. 1983. 37:66-71.

Varnam AH, Sutherland JP. Meat and meat products: technology, chemistry and microbiology. Chapman and Hall, London, UK. 1995. p 167-210.

Wanangkarn A, Liu DC, Swetwiwathana A, Jindaprasert A, Phraephaisarn C, Chumnqoen W, et al. Lactic acid bacterial population dynamics during fermentation and storage of Thai fermented sausage according to restriction fragment length polymorphism analysis. Int J Food Microbiol. 2014. 186:61-67.

Zagorec M, Champomier-Vergès MC. Lactobacillus sakei: a starter for sausage fermentation, a protective culture for meat products. Microorganisms. 2017. 5:56. https://doi.org/10.3390/ microorganisms 5030056 